\title{
A New Property of Phage Group II Staphylococcus aureus Strains: Host Restriction of Phage $\mathrm{K}_{14}$
}

\author{
By DORIS J. RALSTON AND BEATRICE S. BAER \\ Department of Bacteriology, University of California, \\ Berkeley, California, U.S.A.
}

(Received 10 December 1962)

\begin{abstract}
SUMMARY
Various strains of Staphylococcus aureus which type exclusively with phages of lytic group II were found to modify phage K14 so that its ability to form plaques on host Kin was lessened. The restricted phage formed plaques with high efficiency on all strains of lytic group II. In general, it plated at lower titres on strains of lytic groups I, III, IV, and on some strains of miscellaneous typing characteristics; however, there were some variations among separate cultures of the same strains. For example, the restricted phage plated at high titre on strains $52 \mathrm{~A} / 79^{\mathrm{a}}, 73$, and $44 \mathrm{~A}$, but formed significantly fewer numbers of plaques on strain $52 \mathrm{~A} / 79^{\mathrm{b}}$ and on a second culture of 44.A. Strain K1s was found to dissociate into apt (K1Hi) and non-apt ( $\left.\mathrm{K}_{1 \mathrm{~N} 2}\right)$ forms. The probability of plaque development by restricted phage on strain Kis was dependent upon the nutritional state of the cocci and also upon the proportion of apt and non-apt cells. The restriction of phage $K_{14}$ was eliminated during its propagation on all strains other than lytic group II. The unrestricted progeny particles tended to assay at equal titre on all the indicator strains. In all cases the genotype of the phage-susceptibility to host-control-remained unchanged. The observations add to existing data which indicate that strains of phage group II form a genetically distinct group. The suggestion is made that this phenomenon might help in taxonomic classification of strains of $S$. aureus.
\end{abstract}

\section{INTRODUCTION}

Passage of staphylococcal phage $\mathrm{K}_{14}$ through host Staphylococcus aureus strain 51, formerly designated 145 (Ralston \& Krueger, 1954), results in a host-controlled restriction of plaque forming ability for host $S$. aureus strain $\mathrm{K}_{1}$ (Ralston \& Krueger, $1952,1954)$. Only 1 or $2 \%$ of the phage particles released from each infected host 51 bacterium initiates a successful infection and forms a plaque on strain $\mathbf{k}$. Passage of this successful phage through host $\mathrm{k}_{1}$ produces phage particles of equal ability to initiate plaques on both hosts. The parent phage $\mathrm{K}_{1}$ from which the phage $K_{14}$ was isolated is not host alterable. Phage $K_{14}$ is indistinguishable from phage $K_{1}$ on the bases of adsorption capacity, latent period, burst size, thermolability, susceptibility to phage $K_{1}$ rabbit antiserum and ability to induce the formation of a wall-dissolving lysin, virolysin (Ralston, Baer, Liberman \& Krueger, 1961). The restricted form of phage $\mathrm{K}_{14}$ adsorbed to and killed host $\mathrm{K}_{1}$. It caused no lysis and formed no phage in the majority of $K_{1}$ cocci to which it adsorbed. Otherwise this phage is indistinguishable from its unrestricted counterpart. Phage $\mathbf{K}_{14}$, like phage

Vol. 35, No. 3 was issued 10 September 1964 
$\mathrm{K}_{1}$, had a wide host range and was highly virulent. Both phages belong to the serological D group of Rippon (1956).

In the present studies propagating strains for many of the Staphylococcus aureus typing phages and several miscellaneous strains of staphylococci were employed in an attempt to determine which strains could support infection with the restricted phage $K_{14}$ and which strains could impose a restriction on the unaltered phage $K_{14}$. The data supply evidence to show that strains which have the ability to restrict phage $\mathrm{K}_{14}$ are sensitive to group II typing phages.

\section{METHODS}

Media. The various media employed for these studies and referred to in the text, usually by abbreviation, were as follows: tryptose-phosphate (TP) broth and agar (Difco, Detroit, Mich., U.S.A.); trypticase soy (TS) broth and agar (Baltimore Biological Laboratories, Baltimore, Md., U.S.A.); Medium III, composed of TS broth, TP broth, 15 g., yeast extract (Difco), 5 g., distilled water, $1000 \mathrm{ml}$.; Brucella agar (Albimi Laboratories, Brooklyn, New York, U.S.A.).

Phages. The production and plaque assay of the phages $\mathrm{K}_{1}$ and $\mathrm{K}_{14}$ were described previously (Jones \& Krueger, 1951; Ralston \& Baer, 1960). The designations $P_{1}$ and $P_{14}$ used in former publications are the same as the $K_{1}$ phage of Krueger and its variant $K_{14}$. Duplicate sets of typing phages were obtained from the late Dr A. Browne (California Dept. of Public Health, Berkeley, Calif., U.S.A.) and from Dr J. E. Blair (New York Hospital for Joint Diseases, New York, N.Y., U.S.A.). They were stored at $4^{\circ}$ for 1 year prior to use.

The slide assay plaque procedure of Jones \& Krueger (1951) which has been rapid and accurate for estimate of the $\mathrm{K}_{1}$ and $\mathrm{K}_{14}$ phages was not completely adaptable to these phages; therefore the assays were made by the usual Gratia technique on TS agar containing calcium in concentrations according to the known requirement of each phage.

Bacterial strains. Staphylococcus aureus $\mathbf{k} 1$ was isolated from a case of multiple furunculosis in 1926 by $\operatorname{Dr}$ A. P. Krueger. It has been maintained on laboratory media for 37 years, the last 10 years on TP agar. A separate culture of this organism, $S$. aureus no. 11987, was obtained from the American Type Culture Collection (Washington, D.C., U.S.A.). Strain $\mathrm{K} 1$ is typically quite resistant to restricted phage $\mathrm{K}_{14}$ and was the source for single colony isolates of strains Kiv (cf. Results and Table 4). Strains K1nı and K1N2 were derived from strain Kiv. Unless otherwise stated, the strain K1N used in the titrations was equivalent to K1N2 in its resistance to restricted phage.

The specific propagating strains of Staphylococcus aureus obtained from Dr Blair included PS 51 (formerly designated 145), 52A/79 (formerly 925) and 31/44 (formerly 18), received in 1950 ; $3 \mathrm{~A}, 3 \mathrm{~B}, 3 \mathrm{C}, 55,71,29,52 \mathrm{~A} / 79^{\mathrm{a}}, 47,80,6,7,42 \mathrm{E}, 53,54,75,77$, 42D, 81, 42B, 44A and 73, received in 1959; and 187, received in 1961. Strains Ps 39, 44 A, 52, 70, 82 and 523 were obtained from Dr Browne in 1959 to replace those which were no longer viable in the Blair set. Dr Blair also supplied some antibioticresistant strains, recorded by the patient name's (see Table 1). A penicillin sensitivity test strain (probably FDA 209P), designated wR, was obtained from the Western Regional Research Laboratory (Albany, Calif., U.S.A.). Strains 8511, s 68 
$\mathrm{Sr}^{\mathrm{R}} \mathbf{E}^{\mathrm{R}} \mathbf{N}^{\mathrm{R}} \mathrm{Lys}^{+}$(streptomycin resistant, erythromycin resistant, novobiocin resistant, lysogenic for phage 53) and $\mathbf{s} 83 \mathbf{L}-\mathbf{M}^{-}$(lactose non-fermenting, mannitol non-fermenting) were obtained from Dr M. L. Morse (University of Colorado, Denver, Col., U.S.A.).

Phage typing. The method recommended by Blair \& Carr (1960) was used. All of the standard propagating strains of staphylococcus were tested with phages at 1 RTD (routine test dilution). The following phages were used: Group I includes phages 29, 52, 52A, 79, 80; group II includes phages $3 \mathrm{~A}, 3 \mathrm{~B}, 3 \mathrm{C}, 39,55,71,523$; group III includes phages $6,7,42 \mathrm{~B}, 42 \mathrm{E}, 47,53,54,70,73,75,77,83$; group IV includes phage 42D; miscellaneous group includes phages 44A, 81 . A few strains were tested by a procedure modified from that of Hood (1953) in order to determine broad phage group patterns. Microscope slides were layered with $0.5 \mathrm{ml}$. TP agar $(0 \cdot 3 \%)$ containing $3 \times 10^{7} \mathrm{cocci} / \mathrm{ml}$. Mixtures of typing phages at $10^{-2}$ dilution were then spotted on the agar surface with a loop or cotton swab. The phage mixtures were as follows : group I (81) contained phages $29,44 \mathrm{~A}, 52,52 \mathrm{~A}, 79,80,81$; group II contained phages $3 \mathrm{~A}, 3 \mathrm{~B}, 3 \mathrm{C}, 39,55,523$; group III (IV) contained phages 6 , $47,53,54,73,77,83,42 \mathrm{D}, 42 \mathrm{~B}$. The slides were incubated at $28^{\circ}$ in moist chambers for $24 \mathrm{hr}$. The most prominent areas of clearing were recorded. In some instances the strain was retested with individual members of the phage pools.

Plaque isolations. Phage from isolated plaques was suspended in $10 \mathrm{ml}$. sterile $0.85 \% \mathrm{NaCl}$. Known volumes were then mixed with a suspension of the desired strain of staphylococcus and assayed by plaque count.

Detection of restricted phage. Detection was accomplished by simultaneous assay of phage $\mathrm{K}_{14}$ on each of two hosts, one being a test indicator strain and the other being host Kin.

Further description of the detection of restricted phage is presented in the text.

Terms used. The terms describing the observed changes in phage $\mathrm{K}_{14}$ preparations are not intended to express underlying mechanisms. 'Restricted' phages are those which are highly infective for cocci of group II, but are significantly less infective for host K1N. 'Unrestricted' phages are those having a potential for infecting strain K1N equal to that for infecting strains of group II. The symbols K14/51 and K14/K1N represent phage $\mathrm{K}_{14}$ produced on host strains 51 and Kis respectively. 'Restrictor' hosts are those which reduce the infectivity of phage $K_{14}$ for host KiN. 'Releasor' (or derestrictor) hosts are those which yield unrestricted phage $\mathbf{K}_{14}$ after being initially infected with restricted phage. Indicator strains exhibited high or low susceptibility, i.e. were apt or inapt for infection by phage K14. The infection potential refers to the ability of phage $\mathrm{K}_{14}$ to produce plaques on a given assay strain.

\section{RESULTS}

\section{Correlation of phage pattern of Staphylococcus aureus strains with their ability to serve as efficient indicator strains for restricted phage K14/51}

Previously we reported that when phage $\mathrm{K}_{14}$ was restricted by host 51 it formed about 40-fold fewer plaques on host $\mathrm{k}_{1}$ than on host 51 and that it also had a low efficiency of plating for a large number of strains of Staphylococcus aureus. In fact, when restricted phage K14/51 was assayed by plaque count on various $S$. aureus it appeared to divide the strains into two groups: on one group (highly susceptible) 
Table 1. Correlations between specific phage patterns of Staphylococcus aureus and their susceptibilities to restricted and unrestricted forms of phage $K_{14}$ and to the nonhost-controllable parent phage $\mathrm{K}_{1}$

\begin{tabular}{|c|c|c|c|c|c|}
\hline \multirow[b]{2}{*}{$\begin{array}{l}\text { Phage } \\
\text { group }\end{array}$} & \multirow[b]{2}{*}{$\begin{array}{l}\text { Assay } \\
\text { strain }\end{array}$} & \multirow[b]{2}{*}{ Broad phage pattern } & \multicolumn{3}{|c|}{ Phage stock used } \\
\hline & & & $\begin{array}{c}\mathrm{K} 1 / \mathrm{Kl}^{*} \\
\text { non- } \\
\text { controllable } \\
a\end{array}$ & $\begin{array}{c}\mathbf{K 1 4} / \mathbf{K 1} \\
\text { unrestricted } \\
b\end{array}$ & $\begin{array}{c}\mathbf{K 1 4} / \mathbf{5 1} \\
\text { restricted } \\
c\end{array}$ \\
\hline I & $\begin{array}{l}29 \\
52 \\
52 \mathrm{~A} / 79^{\mathrm{a}} \\
52 \mathrm{~A} / 79^{\mathrm{b}} \\
80\end{array}$ & $\begin{array}{l}\text { Propagating strains } \\
\text { I } \\
\text { I } \\
\text { I } \\
\text { I } \\
\text { I, III, } 81\end{array}$ & $\begin{array}{r}<10^{6} \\
5 \cdot 4 \times 10^{9} \\
5 \cdot 3 \times 10^{9} \\
6 \cdot 3 \times 10^{9} \\
4 \cdot 4 \times 10^{9}\end{array}$ & $\begin{array}{r}<10^{2} \\
2.0 \times 10^{9} \\
2.3 \times 10^{9} \\
1.3 \times 10^{9} \\
5.8 \times 10^{9}\end{array}$ & $\begin{array}{r}<10^{4} \\
7 \cdot 5 \times 10^{7} \\
2 \cdot 2 \times 10^{9} \\
4 \cdot 3 \times 10^{7} \\
9 \cdot 0 \times 10^{7}\end{array}$ \\
\hline II & $\begin{array}{l}\text { 3A } \\
\text { 3B } \\
3 \mathbf{C} \\
39 \\
51 \\
55 \\
71 \\
523\end{array}$ & $\begin{array}{l}\text { II } \\
\text { II } \\
\text { II } \\
\text { II } \\
\text { II } \\
\text { II } \\
\text { II } \\
\text { II }\end{array}$ & $\begin{array}{l}6 \cdot 7 \times 10^{9} \\
7 \cdot 0 \times 10^{9} \\
9 \cdot 8 \times 10^{9} \\
8.8 \times 10^{8} \\
1 \cdot 1 \times 10^{10} \\
3 \cdot 1 \times 10^{9} \\
5 \cdot 7 \times 10^{9} \\
7 \cdot 0 \times 10^{9}\end{array}$ & $\begin{array}{l}4.6 \times 10^{9} \\
5.0 \times 10^{9} \\
4.2 \times 10^{9} \\
5 \cdot 2 \times 10^{9} \\
7 \cdot 6 \times 10^{9} \\
8.9 \times 10^{9} \\
6.9 \times 10^{9} \\
1.0 \times 10^{9}\end{array}$ & $\begin{array}{l}6.3 \times 10^{9} \\
6 \cdot 4 \times 10^{9} \\
6.9 \times 10^{9} \\
9 \cdot 4 \times 10^{8} \\
9 \cdot 0 \times 10^{9} \\
2 \cdot 6 \times 10^{9} \\
5 \cdot 7 \times 10^{9} \\
6.7 \times 10^{9}\end{array}$ \\
\hline III & $\begin{array}{l}6 \\
7 \\
42 \mathrm{~B} \\
42 \mathrm{E} \\
47 \\
53 \\
54 \\
70 \\
73 \\
75 \\
77 \\
83\end{array}$ & $\begin{array}{l}\text { III, 81 } \\
\text { III, IV, } 81 \\
\text { III, 81 } \\
\text { III, 81 } \\
\text { III } \\
\text { III } \\
\text { III, 73 } \\
\text { III, 81 } \\
\text { I, II, III } \\
\text { III } \\
\text { III } \\
\text { III, 81, }\end{array}$ & $\begin{array}{r}3.6 \times 10^{9} \\
2.0 \times 10^{9} \\
8.5 \times 10^{9} \\
1.8 \times 10^{9} \\
<10^{6} \\
4.0 \times 10^{9} \\
4.7 \times 10^{9} \\
<10^{6} \\
7.8 \times 10^{9} \\
1.7 \times 10^{9} \\
<10^{6} \\
<10^{6}\end{array}$ & $\begin{array}{c}1 \cdot 2 \times 10^{9} \\
<10^{6} \\
2 \cdot 0 \times 10^{10} \\
7 \cdot 8 \times 10^{8} \\
<10^{2} \\
\text { n.t. } \\
1 \cdot 0 \times 10^{9} \\
<10^{2} \\
2 \cdot 0 \times 10^{9} \\
1 \cdot 3 \times 10^{9} \\
<10^{2} \\
<10^{2}\end{array}$ & $\begin{array}{r}8 \cdot 2 \times 10^{7} \\
<10^{4} \\
1 \cdot 3 \times 10^{8} \\
2 \cdot 8 \times 10^{7} \\
<10^{4} \\
2 \cdot 2 \times 10^{7} \\
4 \cdot 5 \times 10^{7} \\
<10^{4} \\
2 \cdot 2 \times 10^{9} \\
1 \cdot 5 \times 10^{8} \\
<10^{4} \\
<10^{4}\end{array}$ \\
\hline IV & 42D & IV & $2.0 \times 10^{9}$ & $3.6 \times 10^{8}$ & $3.7 \times 10^{7}$ \\
\hline Mise. & $\begin{array}{l}44 \mathrm{~A} \\
187 \\
81\end{array}$ & $\begin{array}{l}\text { I, III, IV } \\
187 \\
\text { I, } 81 \\
\text { Non-propagating strains }\end{array}$ & $\begin{array}{l}\text { 3.4 } \times 10^{9} \\
\text { n.t. } \\
2.7 \times 10^{9}\end{array}$ & $\begin{array}{l}2.1 \times 10^{\circ} \\
\text { n.t. } \\
5.2 \times 10^{9}\end{array}$ & $\begin{array}{l}2.0 \times 10^{9} \\
8.7 \times 10^{7} \\
7.3 \times 10^{7}\end{array}$ \\
\hline Other & $\begin{array}{l}\text { K1N } \\
\text { WR } \\
\text { Gold } \\
\text { Sullivan } \\
\text { Gillespie } \\
\text { Bradley } \\
\text { Morse s68 } \\
\text { Morse s83 } \\
\text { Morse } \\
\text { 8511 } \\
\text { Dodge }\end{array}$ & $\begin{array}{l}\text { I, II, III, IV, } 81 \\
\text { I, IV } \\
\text { I } \\
\text { I } \\
\text { III } \\
\text { III } \\
\text { III } \\
\text { III } \dagger \\
\text { III }\end{array}$ & $\begin{array}{r}6.3 \times 10^{9} \\
4.7 \times 10^{9} \\
5.0 \times 10^{9} \\
5.7 \times 10^{9} \\
5.3 \times 10^{9} \\
5.5 \times 10^{8} \\
<10^{8} \\
2.1 \times 10^{9} \\
1.4 \times 10^{9} \\
5.7 \times 10^{9}\end{array}$ & $\begin{array}{l}2.9 \times 10^{9} \\
4.8 \times 10^{9} \\
\text { n.t. } \\
\text { n.t. } \\
\text { n.t. } \\
\text { n.t. } \\
\text { n.t. } \\
\text { n.t. } \\
\text { n.t. }\end{array}$ & $\begin{array}{r}8.6 \times 10^{7} \\
7 \cdot 2 \times 10^{7} \\
5 \cdot 1 \times 10^{7} \\
1 \cdot 0 \times 10^{8} \\
1 \cdot 8 \times 10^{7} \\
<10^{4} \\
<10^{4} \\
1 \cdot 3 \times 10^{7} \\
6.5 \times 10^{7}\end{array}$ \\
\hline
\end{tabular}

* K1/K1 designates phage $\mathrm{K} 1$ produced on host, $\mathrm{K} 1$, etc. n.t. $=$ not tested.

$\dagger$ Broad phage pattern determined by testing with pools. 
phage $\mathrm{K} 14 / 51$ formed plaques roughly equivalent in number to those produced on host 51, and on the other group, the phage formed many fewer plaques, their number being equivalent to those produced on strain $\mathrm{K}_{1}$ (Ralston \& Krueger, 1954). In the present study this apparent division of response of staphylococcal strains to restricted phage $\mathrm{K}_{14}$ has been further investigated to determine whether it might be related to a particular pattern of susceptibility to individual typing phages. For this analysis over 40 coccal strains were classified as to phage-typing pattern and then were tested for their relative susceptibility to infection and plaque formation by restricted phage $\mathrm{K} 14 / 51$, by unrestricted phage $\mathrm{K14} / \mathrm{K1}$, and by the non-host controllable parent phage $\mathrm{K1} / \mathrm{K} 1 \mathrm{~N}$. In the data shown in Table 1, the strains are grouped according to the broad phage-typing patterns as determined in our laboratory by the method of Blair \& Williams (1961). These patterns were in general agreement with the results reported by Williams \& Rippon (1952), Blair \& Carr (1960), Wallmark \& Finland (1961), and Blair \& Williams (1961).

As indicated in Table 1 , the non-controllable phage $\mathrm{K1} / \mathrm{K1N}$ tended to form equivalent numbers of plaques on all susceptible strains, the titres being mainly in the range of $10^{9} / \mathrm{ml}$. (column $a$ ). The unrestricted phage $\mathrm{K} 14 / \mathrm{K} 1$ was much like the parent phage $\mathrm{K} 1 / \mathrm{K} 1 \mathrm{~N}$ (column $b$ ). In these tests certain strains were resistant to all preparations of the $K_{1}$ or $K_{14}$ phage: PS 29, 47, 70, 77 and 83. The restricted phage K14/51 (column $c$ ) divided the strains of Staphylococcus aureus into two groups, and these groups were correlated with their typing patterns as follows: (a) all strains susceptible to group II phages (i.e. forming lytic patterns with group II phages at 1 RTD) were highly susceptible to the restricted K14/51 phage-titres in the range of $10^{\%} / \mathrm{ml}$; whereas $(b)$ most strains not typing with group II phages were significantly less susceptible-titres in the range of $10^{7} / \mathrm{ml}$. We suggest that the group II strains possess a property which confers on them a high degree of susceptibility to plaque formation by group II typing phages and that this property also controls their susceptibility to restricted phage K14/51. However, there are some unexplainable exceptions, since strains PS 73, 52A $/ 79^{\mathrm{a}}$ and 44A did not type solely with group II phages but underwent good plaque formation with phage $\mathrm{K} 14 / 51$, the phage titre being equivalent to that on host 51 .

\section{Restriction of phage $K_{14}$ by other strains of Staphylococcus aureus, a property of phage group II cocci}

The restrictor host, Staphylococcus aureus 51, used for the studies of Table 1 is known to belong to phage group II. Tests were next performed to determine which of the other staphylococcal strains would restrict or fail to restrict phage $\mathrm{K}_{14}$, and which strains would serve as efficient indicator hosts for the restricted phage. A phage lysate of unrestricted phage $\mathrm{K} 14 / \mathrm{K} 1 \mathrm{~N}$ prepared in medium III broth was diluted in saline and plated with each $S$. aureus strain in TP agar. The contents of one or two typical phage plaques from each passage were suspended in saline, diluted, and assayed on hosts representative of the broad lytic phage groups. Upon each plaque passage the titre of the phage for a given indicator host was compared to the titre for host Kiv. The plaques $/ \mathrm{ml}$. formed on the indicator host $(\mathbf{H})$ were then divided by the plaques/ml. formed on host Kis. The resultant quotient represented the efficiency of plating (EOP) $\mathrm{H} / \mathrm{K}_{1 \mathrm{~N}}$ of phage from a given passage for any given assay host, relative to host $\mathrm{K}_{1 \mathrm{~N}}$. This procedure also served as a means of detecting 


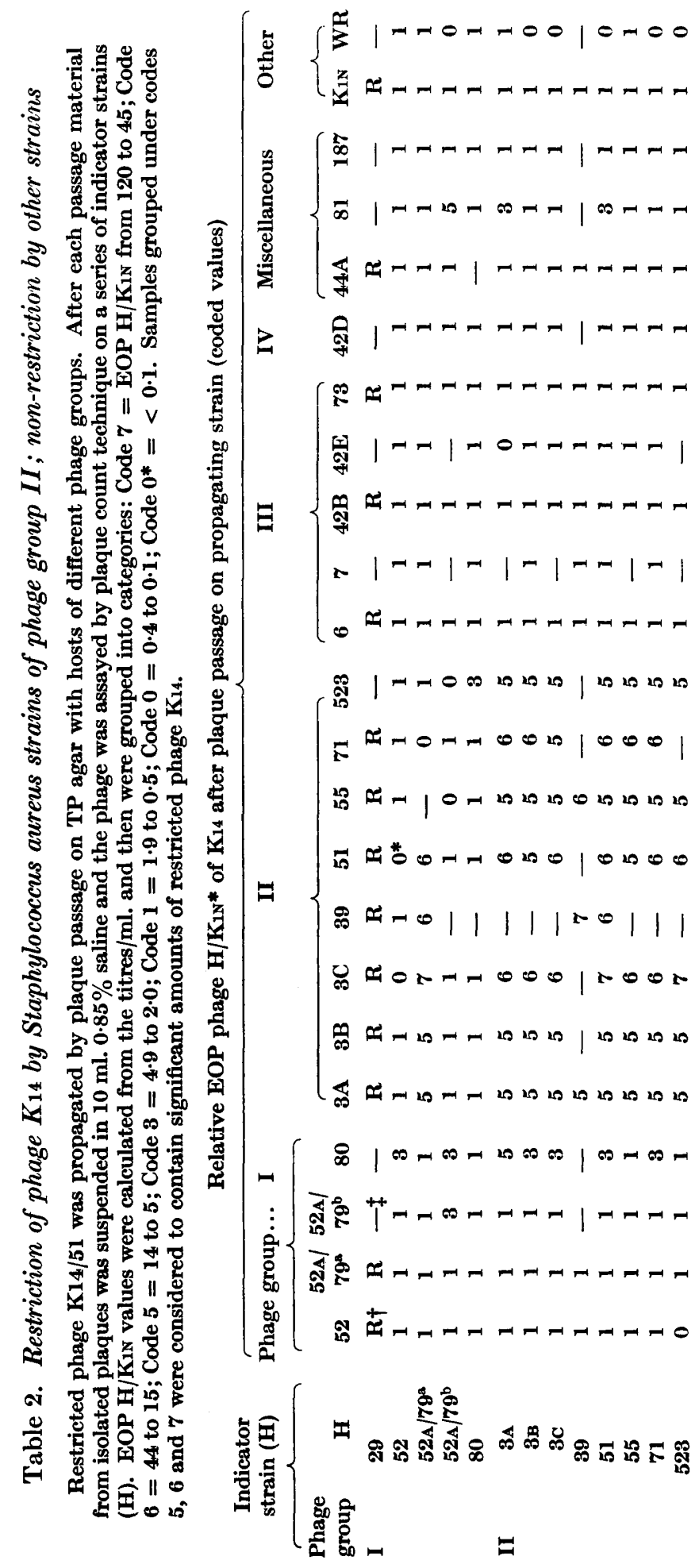




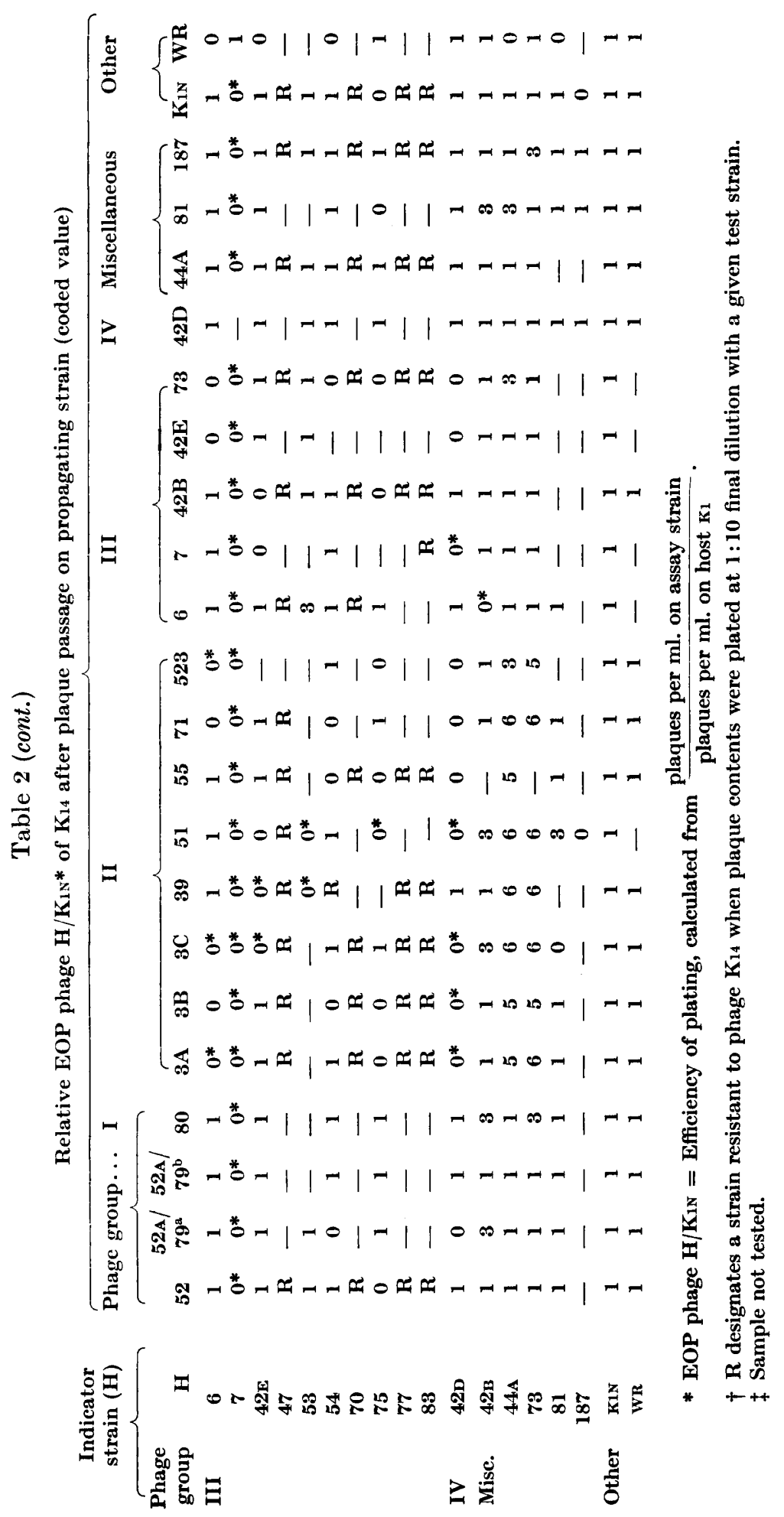


the presence of restricted phage particles. For example, when the phage $\mathrm{K}_{14}$ formed a number of plaques on any given indicator strain equal in number to the plaques produced by the same volume of phage on host K1n, the EOP H/K1N of the phage for the test indicator host was equal to 1 . This indicated there were no restricted particles. When more plaques were produced on the test strain than on host Kis, the EOP $H / K_{1 N}$, was greater than 1, reflecting the presence of restricted phage particles.

To simplify the comparison of the numerous plaque passages and the subsequent ability of the phage $\mathrm{K}_{14}$ to form plaques on different assay strains, the various EOP $\mathrm{H} / \mathrm{K}_{1 \mathrm{~N}}$ values were grouped into categories, coded $7,6,5,3,1,0,0^{*}$, as recorded in Table 2. An EOP $\mathrm{H} / \mathrm{K}_{1 \mathrm{~N}}$ assigned to group 5 is considered to represent a significant restriction of the phage; it indicates that a range of from 5 to 14 plaques had appeared on a given indicator strain for each plaque on host Kis. By comparing the titres of phage $\mathrm{K}_{14}$ from single plaque passages for a series of indicator strains with the titres for host K1v, we could tell at a glance which strains behaved like strain 51 and which strains behaved like host Kiv. In Table 2 the strains of Staphylococcus aureus that were used to propagate and to assay phage $K_{14}$ have been classified according to their broad phage-typing patterns. The results may be summarized as follows: (1) In addition to strain 51, all other strains of phage group II were capable of restricting phage $\mathrm{K}_{14}$ for host $\mathrm{K}_{1 \mathrm{~N}}$ (code numbers 7, 6 and 5). The ability to host-restrict phage $\mathrm{K}_{14}$ appears to be confined to group II strains. (2) When phage $\mathrm{K}_{14}$ had been produced on and restricted by a given strain of phage group II, all other strains within phage group II served as effective indicator hosts although there were differences in their relative susceptibilities. (3) Propagating strains that were not members of phage group II yielded unrestricted phage $\mathbf{K}_{14}$ (code 3, 1, 0, $0^{*}$ ). When these 'non-group' II strains were tested for their ability to serve as indicator host for the assay of restricted phage $K_{14}$, they proved to be relatively inapt, i.e. the restricted phage produced many fewer plaques on these strains than on strains belonging to phage group II. Strains $44 \mathrm{~A}, 52 \mathrm{~A} / 79^{\mathrm{a}}$ and 73 were exceptions, being highly susceptible to the restricted phage regardless of the group II host employed as the source of the phage. In contrast to the group II coccal strains, however, none of these three hosts restricted phage $K_{14}$. (4) In general, hosts classified as restrictors of phage $K_{14}$ reduced but did not abolish the ability of the phage to propagate on host $\mathrm{kiN}$, as evidenced by the fact that samples containing several hundred particles of restricted phage generally formed a few plaques on host K1s. During these studies certain bacterial hosts have tended to be slightly more resistant than others to plaque formation by unrestricted phage $\mathrm{K} 14 / \mathrm{K} 1 \mathrm{~N}$ : PS 6, 7, 42E, 75 and 42D. Of these, strain 7 showed quite a variation, sometimes being highly resistant, the phage forming no plaques even in concentrated $\left(10^{8} / \mathrm{ml}\right.$.) amounts. We have noticed that four out of five of these strains are susceptible mainly to group III phages and that several other strains which are completely resistant also show lytic group III typing characteristics, i.e. PS 47, 70, 77 and 83. Perhaps group III cocci possess metabolic patterns which tend to be unfavourable for successful infection by phage $\mathrm{K}_{14}$. If so, then the change brought about by group II restrictor hosts might reflect a capacity to lower the ability of phage $\mathbf{K}_{14}$ to replicate in a generally unfavourable metabolic environment. 


\section{The interaction of restricted phage $\mathrm{K} 14$ with cocci from strains other than phage group II}

Most of our information concerning the interaction between restricted phage and Staphylococcus aureus strains on which it does not form plaques efficiently has been obtained from studies with the Kis strain. Suggestive evidence that an early step in phage infection is blocked as a result of the restriction was obtained from the following preliminary observations: (1) Phage-adsorbed cocci showed no detectable increase in ultraviolet adsorption at 260 or $280 \mathrm{~m} \mu$, indicating that no net synthesis of protein or nucleic acid had occurred, in contrast to the increases normally following injection of phage material into the cell. (2) The lytic enzyme, virolysin, was not detected; normally this enzyme is produced early in the latent period (Ralston et al. 1961). (3) The phage-adsorbed cocci remained susceptible to infection with the unrestricted phage $\mathrm{K}_{14}$, indicating that during the early steps after adsorption the restricted phage did not cause the cell to produce materials which might inhibit the synthesis of unrestricted phage. There is as yet no evidence as to the exact step past adsorption which has been blocked.

We have found that several variables determine whether restricted phage $\mathrm{K}_{14}$ can initiate a plaque. For example, with the Kiv strain, aptness for infection with the restricted phage K14/51 increases during the logarithmic phase of growth (Ralston $\&$ Krueger, 1954). The number of cells that can support infection are also influenced by changes in the medium of the cells prior to infection. In these studies Staphylococcus aureus $\mathrm{K}_{1}$ (' $\mathrm{N}$ ' form) was grown for $24 \mathrm{hr}$ periods at $37^{\circ}$ either on TP agar or on Brucella agar. After 10 and 20 daily transfers the culture that had been carried on Brucella agar was transferred to TP agar. Cells from each transfer were stored at $4^{\circ}$, and finally a transfer was made from each passage, thus resulting in a series of cultures which had been incubated at $37^{\circ}$ for $24 \mathrm{hr}$. These cultures were then tested for their relative susceptibilities to restricted phage K14/51. Simultaneously the phage was assayed on strain 51. The data in Table 3 record the number of plaques/ ml. developing on each culture and the EOP $51 / K_{1}$ values calculated with respect to each K1 preparation. During the first transfer on Brucella agar the susceptibility of Kin cocci decreased significantly, the EOP 51/K1 changing from 62 to 280. After continued transfer on Brucella agar, $\mathrm{K}_{1}$ cocci showed a slight increase in susceptibility to restricted $\mathrm{K}_{14}$, but not to the level of $\mathrm{K}_{1}$ cocci maintained on $\mathrm{TP}$ agar. When the culture was returned to TP agar after the 10th and 20th transfer on Brucella medium, it immediately increased in susceptibility to the restricted phage $\mathrm{K}_{14}$, to equal that of cocci maintained continuously on TP agar.

Detection of apt and non-apt forms of Staphylococcus aureus $K_{1}$. We have recognized that with any restricted phage-host system, either the phage or the host cells-or both-might contain mixtures of infective (plaque-forming) and non-infective particles or apt and non-apt cells. An early observation that identical amounts of phage K14/51 plates with low but approximately equal efficiencies on a large number of strains of Staphylococcus aureus prompted us to suggest that lysates of restricted phage contained a low percentage of phage particles possessing a high potential for infecting strain 51 mixed with a large percentage of particles possessing a low potential for forming plaques on many other strains (Ralston \& Krueger, 1954). However, since it is now known that most of these relatively insusceptible 
strains type mainly with group III phages, this observation might be explained equally as well by differences in the general metabolic patterns of susceptible and less susceptible hosts. If there exist mixtures of particles in stock preparations of restricted phage, their physical separation would require the use of a highly sensitive technique; for we have been unable to detect their presence by methods based on adsorption rates, temperature stability, on rates of inactivation by specific antiserum, or by ultraviolet irradiation.

\section{Table 3. Effect of growth medium on susceptibility of Staphylococcus aureus $K_{1}$ to restricted phage $K 14 / 51$}

K1 (ATC culture no. 11987), previously incubated on TP agar, was grown on each medium for $24 \mathrm{hr}$ at $37^{\circ}$, for 3 series of 10 transfers; and each transfer was stored at $4^{\circ}$. After each 9th transfer a 24-hr culture was prepared from each stored sample; the cocci were resuspended in TP broth to $6 \times 10^{7} / \mathrm{ml}$., mixed with $0.5 \mathrm{ml}$. of phage $/ \mathrm{K14} / \mathrm{51}$ diluted in saline, and $2.5 \mathrm{ml}$. TP $0.75 \%$ agar, and plated for relative plaque counts. Simultaneously assays were made with strain 51 on TP agar. The EOP 51/K1 values were calculated from the plaque titres.

Growth medium prior to infection with $5 \times 10^{9} / \mathrm{ml}$. particles of phage $/ \mathrm{K} 14 / 51$

\begin{tabular}{|c|c|c|c|c|}
\hline \multirow[b]{2}{*}{$\begin{array}{l}\text { Transfer } \\
\text { no. }\end{array}$} & \multicolumn{2}{|c|}{ Tryptose-phosphate agar } & \multicolumn{2}{|c|}{ Brucella agar } \\
\hline & $\begin{array}{c}\text { Plaques/ml. } \\
\times 10^{7}\end{array}$ & EOP $51 / K_{1}$ & $\begin{array}{c}\text { Plaques/ml. } \\
\times 10^{7}\end{array}$ & $\operatorname{EOP} 51 / K_{1}$ \\
\hline $\mathbf{1}$ & $8 \cdot 0$ & 62 & $1 \cdot 8$ & 280 \\
\hline 2 & n.t. & n.t. & $1 \cdot 8$ & 280 \\
\hline $\mathbf{3}$ & n.t. & n.t. & $\mathbf{3} \cdot \mathbf{3}$ & 150 \\
\hline 4 & n.t. & n.t. & $2 \cdot 6$ & 190 \\
\hline 5 & n.t. & n.t. & $3 \cdot 1$ & 160 \\
\hline 6 & n.t. & n.t. & $2 \cdot 7$ & 185 \\
\hline 7 & n.t. & n.t. & $4 \cdot 6$ & 109 \\
\hline 8 & n.t. & n.t. & $2 \cdot 2$ & 228 \\
\hline 9 & n.t. & n.t. & $\mathbf{2} \cdot \mathbf{3}$ & 218 \\
\hline 10 & $10 \cdot 0$ & 50 & $2 \cdot 8$ & 178 \\
\hline 20 & 5.7 & 87 & & 167 \\
\hline 21 & $8 \cdot 0^{2}$ & 62 & $2 \cdot 5$ & 200 \\
\hline 22 & $10 \cdot 0$ & 50 & $2 \cdot 5$ & 200 \\
\hline 23 & 9.0 & 55 & $1 \cdot 8$ & 280 \\
\hline 24 & $9 \cdot 6$ & 53 & $1 \cdot 8$ & 280 \\
\hline 25 & $\mathbf{9 \cdot 2}$ & 54 & $1 \cdot 6$ & 312 \\
\hline 26 & $8 \cdot 2$ & 61 & 3.7 & 135 \\
\hline 27 & $8 \cdot 0$ & 62 & $1 \cdot 4$ & 358 \\
\hline 28 & $6 \cdot 2$ & 80 & $1 \cdot 6$ & 312 \\
\hline 29 & $5 \cdot 8$ & 86 & $2 \cdot 0$ & 250 \\
\hline 30 & $5 \cdot 6$ & 89 & $1 \cdot 3$ & $\mathbf{3 8 3}$ \\
\hline
\end{tabular}

(Arrows indicate transfers discussed in test.)

In contrast to the lack of evidence for a mixture of particles in restricted phage preparations, we have recently succeeded in separating apt and non-apt cell types from an atypical Kin strain. Both types were obtained from a stock Kin culture which had changed from low to high susceptibility to phage K14/51. The change was first noticed after the culture had undergone numerous daily transfers on TP agar (Table 4). Since their isolation each of these two types has maintained its charac- 
teristics with respect to phage $\mathrm{K14} / \mathbf{5 1}$. One culture, designated $\mathrm{K} 1 \mathrm{H}$, is a susceptible indicator strain. On this strain phage K14/51 forms plaques at titres almost equal to strain 51. The second culture, K1N2, is less susceptible; on this strain the phage 14/51 plates at significantly lower titres.

There may be other strains of Staphylococcus aureus which undergo changes similar to the $\mathrm{K}_{1}$ culture. For example, strains $73,44 \mathrm{~A}$, and $52 / 79^{\mathrm{a}}$ were efficient indicators for restricted phage $K_{14}$, the titres on these strains being equivalent to titres on strain $\mathrm{K}_{1 \mathrm{Hi}}$ or on hosts belonging to phage group II. In contrast, strain $52 \mathrm{~A} / 79^{\mathrm{b}}$ and one other culture of strain 44. A tested 9 years previously were resistant to the restricted phage $K_{14}$ and, therefore, were similar to the typical Kin2 culture. Possibly strains $52_{\mathrm{A}} / 79^{\mathrm{b}}$ and 44A represent forms arising in the populations by mutation. We have noted that 52A/79, 44.A and 73, like both types of strain $\mathrm{k}$, are susceptible to phages from group I (although the $\mathrm{K}_{1}$ culture and strain 73 are susceptible to additional phages). Perhaps strains typable with group I phages possess a metabolism which allows a greater percentage of successful infections with restricted phage.

Table 4. Apt and non-apt colonies of Staphylococcus aureus $\mathbf{k 1 N}$ as shown by differences in EOP 51/K1N values with restricted phage K14/51

Strain k1N represents a single colony isolated from the parent k1 stock culture. During transfer it became highly sensitive to the restricted phage $K_{14}$, the ratio $51 / K_{1 N}$ changing from 65 to 7 .

$\begin{array}{cc}\begin{array}{c}\text { Isolate } \\ \text { no.* }\end{array} & \begin{array}{c}\text { EOP 51/K1N } \\ \text { isolate }\end{array} \\ 1 & 7 \\ 4 & 43 \\ 12 & 7 \\ 13 & 14 \\ 14 & 65 \\ \text { A } & 1 \\ \text { B } & 15 \\ \text { C } & 42 \\ \text { Stock culture } & 7\end{array}$

* Isolates on TS agar were all off-white, round, slightly raised centres; they were typical staphylococci in morphology when viewed at $900 \times$. Strain k1N2 came from no. 4; strain K1H! from $A$.

\section{Release of restriction by strains other than group $I I$}

Hosts other than group II which had been infected with unrestricted phage $\mathrm{K} 14 / \mathrm{K} 1 \mathrm{~N}$ continued to produce the unrestricted form, as evidenced by the fact that the phage progeny from these hosts generally formed equivalent numbers of plaques on all the strains (Codes 3, 1, 0, Table 2). Whenever these hosts were infected with the restricted form of $\mathrm{K}_{14}$ (Table 5), they yielded phage which subsequently formed equal numbers of plaques on assay strains of all the various phage groups. Experimental data showed that similar effects occurred when restricted phage infected strains $\mathrm{K}_{1 \mathrm{~N} 2}, \mathrm{~K}_{1 \mathrm{H}}$ as well as $\mathrm{PS} 52 \mathrm{~A} / 79^{\mathrm{a}}, 73$ and 44A. In effect, then, all these cultures, once infected, can raise the plaque-forming potential of restricted phage $\mathrm{K}_{14}$ despite any differences in their relative susceptibility to restricted particles. This can be regarded as a second kind of host-control-release of the restriction which had been imposed by strains of phage group II. From this it may be con- 


\section{Table 5. Release of restriction of phage K14/51 by non-group II strains}

$$
\text { of Staphylococcus aureus }
$$

Phage K14/51 was propagated by plaque passage on TP agar. Material from isolated plaques was suspended in $0.5 \%(w / v)$ saline and assayed by plaque count technique on a series of $S$. aureus assay strains $(H)$ of known phage group. From the relative tirres $/ \mathrm{ml}$. the EOP $\mathrm{H} / \mathrm{K}_{1} \mathrm{~N}$ values were calculated. Prior to passage on each propagating strain, the restricted phage had an EOP 51/K1N $=40$.

\begin{tabular}{|c|c|c|c|c|c|c|}
\hline \multirow{3}{*}{$\begin{array}{l}\text { Phage } \\
\text { group } \\
\text { of strain }\end{array}$} & \multirow{3}{*}{$\begin{array}{c}\text { Assay } \\
\text { strain } \\
(\mathbf{H})\end{array}$} & \multicolumn{5}{|c|}{ EOP $H / K_{1 N}$ of phage $K 14 / 51$ after one plaque passage } \\
\hline & & \multicolumn{2}{|c|}{$\mathbf{I}$} & \multicolumn{2}{|c|}{ III } & \multirow{2}{*}{$\begin{array}{c}\text { Other } \\
\text { Kin }\end{array}$} \\
\hline & & $\mathbf{5 2 A} / 79^{a}$ & 44A & 42E & 73 & \\
\hline \multirow[t]{2}{*}{$\mathbf{I}$} & $\mathbf{5 2}$ & $\mathbf{1} \cdot \mathbf{0}$ & 0.7 & $\mathbf{0 . 2}$ & $\mathbf{1} \cdot \mathbf{0}$ & $\mathbf{0 \cdot 1}$ \\
\hline & $52 \mathrm{~A} / 79^{2}$ & $1 \cdot 6$ & $1 \cdot 8$ & 0.8 & $1 \cdot 0$ & $\mathbf{1 \cdot 6}$ \\
\hline \multirow[t]{2}{*}{ II } & 39 & $\mathbf{1} \cdot \mathbf{6}$ & 0.8 & 0.5 & $0 \cdot 5$ & $1 \cdot 0$ \\
\hline & 51 & 0.6 & $1 \cdot 3$ & $0 \cdot 4$ & 0.5 & 1.5 \\
\hline \multirow[t]{6}{*}{ III } & 6 & $1 \cdot 0$ & 1.5 & $0 \cdot 1$ & 1.0 & 0.2 \\
\hline & 7 & $0 \cdot 1$ & $0 \cdot 1$ & $0 \cdot 1$ & $0 \cdot 1$ & 0.6 \\
\hline & $42 \mathrm{E}$ & 0.4 & $0 \cdot 6$ & 0.5 & 0.5 & $0 \cdot 3$ \\
\hline & $\mathbf{5 3}$ & $1 \cdot 6$ & $1 \cdot 0$ & $0 \cdot 6$ & $1 \cdot 0$ & 1.7 \\
\hline & 42B & $3 \cdot 0$ & $2 \cdot 4$ & $1 \cdot 0$ & 1.0 & 1.9 \\
\hline & 73 & $1 \cdot 6$ & 1.4 & 0.7 & $1 \cdot 0$ & $1 \cdot 0$ \\
\hline Other & $\mathbf{K}_{1 \mathbf{N}}$ & 1.0 & 1.0 & $1 \cdot 0$ & 1.0 & $1 \cdot 0$ \\
\hline
\end{tabular}

Table 6. Phenotypic changes of phage $K_{14}$ during serial passage on strains of Staphylococcus aureus in TP agar

Phage K14 was propagated by plaque technique. Material from isolated plaques was suspended in saline and assayed on strain 51 (group II), on host k1N, and on representative strains of known phage group. Phage $\mathrm{K}_{14}$ was considered to be restricted when the titre/ml. for strain 51 was greater than five-fold (usually 20-fold), the titre/ml. for strain K1N; it was considered to be unrestricted when the titre/ml. for strain 51 was equivalent to the titre/ml. for strain K1N.

\begin{tabular}{|c|c|c|c|c|c|c|c|}
\hline \multicolumn{2}{|c|}{ Stock phage } & \multicolumn{2}{|c|}{ Passage no. 1} & \multicolumn{2}{|c|}{ Passage no. 2} & \multicolumn{2}{|c|}{ Passage no. 3} \\
\hline $\begin{array}{l}\text { Initial } \\
\text { host }\end{array}$ & $\begin{array}{l}\text { Effect on } \\
\text { phage } K_{14}\end{array}$ & Host & $\begin{array}{c}\text { Effect on } \\
\text { phage } K_{14}\end{array}$ & Host & $\begin{array}{r}\text { Effect on } \\
\text { phage } K_{14}\end{array}$ & Host & $\begin{array}{r}\text { Effect on } \\
\text { phage } K_{14}\end{array}$ \\
\hline K1N & Unrestricted & $\begin{array}{lc}\rightarrow & 523 \\
\rightarrow & 51 \\
\rightarrow & 3 \mathrm{C}\end{array}$ & $\begin{array}{l}\text { Restricted } \\
\text { Restricted } \\
\text { Restricted }\end{array}$ & $\begin{aligned} & - \\
\rightarrow & 31 / 44 \\
\rightarrow & \mathrm{K} 1 \mathrm{~N} \\
\rightarrow & 3 \mathrm{~A}\end{aligned}$ & $\begin{array}{l}\qquad \frac{-}{-} \\
\text { Unrestricted } \\
\text { Unrestricted } \\
\text { Restricted }\end{array}$ & $\begin{array}{l}- \\
- \\
-\end{array}$ & $\begin{array}{c}- \\
- \\
-\end{array}$ \\
\hline 51 & Restricted & $\begin{array}{lr}\rightarrow & 39 \\
\rightarrow & 7 \\
\rightarrow & 73 \\
& \rightarrow \mathrm{K} 1 \mathrm{~N}\end{array}$ & $\begin{array}{l}\text { Restricted } \\
\text { Unrestricted } \\
\text { Unrestricted } \\
\text { Unrestricted }\end{array}$ & $\begin{array}{l}\rightarrow 39 \\
\rightarrow 42 \mathrm{~B} \\
\rightarrow \mathrm{K1N} \\
\rightarrow 51 \\
\rightarrow 42 \mathrm{~B} \\
\rightarrow 42 \mathrm{E} \\
\rightarrow 52 \\
\rightarrow 52 \mathrm{~A} / 79 \\
\rightarrow 73 \\
\rightarrow 7\end{array}$ & $\begin{array}{l}\text { Restricted } \\
\text { Unrestricted } \\
\text { Unrestricted } \\
\text { Restricted } \\
\text { Unrestricted } \\
\text { Unrestricted } \\
\text { Unrestricted } \\
\text { Unrestricted } \\
\text { Unrestricted } \\
\text { Unrestricted }\end{array}$ & $\begin{array}{l}- \\
- \\
- \\
- \\
- \\
- \\
- \\
- \\
\rightarrow 42 B \\
\rightarrow \text { K1N } \\
\rightarrow 51 \\
\rightarrow 71\end{array}$ & $\begin{array}{l}-\bar{z} \\
- \\
- \\
- \\
- \\
- \\
- \\
\text { Unrestricted } \\
\text { Unrestricted } \\
\text { Restricted } \\
\text { Restricted }\end{array}$ \\
\hline
\end{tabular}


cluded that the ability of a strain to release the restriction is distinct from that property which confers on it a susceptibility to infection and plaque formation by restricted phage $\mathrm{K}_{14}$. (Of course, were any group II hosts able to reduce the potential of phage $\mathrm{K}_{14}$ for other hosts to zero, these non-apt hosts could not be tested for their ability to release the restriction.)

In additional tests phage $\mathrm{K}_{14}$ was propagated serially by plaque passage on strains selected at random from all groups and tested for its relative ability to infect Kin, the host of propagation, and strains of phage group II. The phage was restricted and released from restriction according to the phage group of the host. The phage remained phenotypically alterable, regardless of the propagating host (Table 6).

With hosts K1N and 51, control over the plaque-forming potential of the phage $\mathrm{K}_{14}$ has been demonstrated to occur within each single burst cycle of an infected cell (Ralston \& Krueger, 1954). While single burst studies have not been performed during the present studies, the results of single plaque passages indicate that the same changes are involved.

\section{DISCUSSION}

Strains with group II phage patterns, a genetically distinct group of Staphylococcus aureus

Strains of Staphylococcus aureus can be divided into broad but often overlapping groups based upon their ability to be lysed by specific phages (Williams $\&$ Rippon, 1952), lysogenic interrelationships (Williams Smith, 1948a; Rountree, 1949a), the nature of surface antigens (Cowan, 1939; Oeding \& Williams, 1958), the ease with which antibiotic resistance develops (Barber \& Whitehead, 1949; Barber \& Burston, 1955; Wallmark \& Finland, 1961), and the antigenic specificity of their free coagulases (Barber \& Wildy, 1958). Phage-typing studies have established the fact that group II strains of human origin behave as a distinct group, rarely forming patterns with phages from other groups (Rippon, 1956) or carrying phages for other groups (Rountree, 1949a; Della Vida, 1957). According to our present data, strains of $S$. aureus in phage group II can be distinguished from those in other groups by their unique ability to host-restrict the polyvalent phage $K_{14}$ for most hosts other than those of group II. It appears, however, that sensitivity of the hosts to group II phages is not the sole prerequisite for the host-controlled restriction to occur because strains $\mathrm{K} 1$ and $\mathbf{7 3}$ are susceptible to the group II phages but are incapable of restricting phage $\mathrm{K}_{14}$. Perhaps the ability to exclude phages other than those of group II is a second requirement in order for the host to possess the ability to restrict phage $\mathrm{K}_{14}$. The host-controlled restriction may reflect an interaction with a specific basic structure or region of the group II genome (or some product under its control), and therefore knowledge of this phenomenon may be useful in the taxonomic description of staphylococci, particularly of untypable strains.

\section{Patterns of host-control of staphylococcal phages}

Host-directed changes in staphylococcal phages occur both with phages of high virulence and wide host range (such as phage $\mathrm{K}_{14}$ ) and with the more temperate and specific typing phages. Data from host-control experiments with staphylococcal 
phage Col of B serology, phage 47C of A serology (Rountree, 1956), and phage K14 of $\mathbf{D}$ serology show that phages of widely different serology may be subject to host control.

The controls described by Rountree (1956) involved specific restrictions of host range for strains typing with phages of groups I and III and with $42 \mathrm{~B}$ and $47 \mathrm{C}$ (now classified as miscellaneous). These changes appear to have been confined to specific organisms within the strains of groups I and III and miscellaneous typing characteristics which had been selected for investigation. The K14 controls, on the other hand, have involved changes en bloc of its infectivity for group II and groups other than group II. In other investigations we have observed still another group IInon-group II control: Phages of the group II series were phenotypically altered by passage through strains Kin and 73, so that the group II phages could no longer easily infect group II hosts. At the same time their potential for infecting group III strains was increased (Ralston \& Baer, 1964a,b). Using the phage 3C (serology A), we found that on the first burst from host $\mathrm{K}_{1 \mathrm{~N}}$, the progeny phage $3 \mathrm{C} / \mathrm{K}_{1 \mathrm{~N}}$ particles no longer could form plaques on strain $3 \mathrm{C}$ but plated at high titre on strains $\mathrm{K} 1 \mathrm{~s}, 6$, 42E, 53, 54 and 47. A similar result was obtained by passaging the phage $3 \mathrm{C}$ directly on those group III strains for which it already had an infection potential (extremely low-in the range of $10^{-6}$ to $10^{-8}$ ). Other members of the group II phage series, including phage 55 (serology $\mathbf{B}$ ), underwent similar controls, the chief differences lying in the potentials for infecting specific strains of groups II and III (Ralston \& Baer, 1964b).

\section{Mechanism of host-control}

The exact nature of the host-controlled restriction of staphylococcal phages is not yet known. Neither the alteration of phage $\mathrm{K}_{14}$ nor of phage $3 \mathrm{C}$ (Ralston \& Baer, $1964 b)$ appears to involve interference with their abilities to adsorb to the host bacterium. This is not unexpected because both the polyvalent phage $K_{14}$ and the specific typing phages (Rountree, 1947) adsorb to a wide range of staphylococci regardless of their ability to form plaques. Phage specificity in these systems seems likely to involve mechanisms for penetration of DNA and establishment of phage replicating machinery. Probably the changes which bring about the restriction concern phage structures (protein, DNA, or both) which function in these early steps.

On the part of the restricting host, it would seem logical to investigate the possibility that the restriction results from an interaction between a carried phage-or cellular product thereof-and the phage $\mathbf{K}_{14}$ particle. In general, the hosts of group II are susceptible to and are lysogenic for A, B and F phages (Rountree, 1949b; Rippon, 1956), and their specific phage-typing patterns are in part determined by their carried phages (Williams Smith, 1948b; Rountree, 1949a). However, the $\mathrm{K}_{14}$ phage infects all the group II strains tested by us and is restricted by all, irrespective of their known lysogeny. Therefore, if a prophage-phage $\mathrm{K}_{14}$ genome interaction occurs, it probably involves one carried in common by all group II hosts rather than one which confers strain specific patterns within the group. It would be equally logical to study the possibility that prophages are involved in protecting a given host from infection by a restricted phage particle, or that they might contribute to the formation of a particle with increased plaque-forming 
abilities, should infection be established, thus releasing the restriction. Evidence to support both possibilities was presented by Christensen (1961) for a Shigella dysenteriae-phage $\mathrm{P}_{2}$ and $\mathrm{T}_{1}$ system. However, the staphylococcal host kis does not appear to be lysogenic, yet it is capable of releasing the restriction.

This investigation has been supported by funds from grant No. AI-03776 from the National Institutes of Health, U.S. Public Health Service.

\section{REFERENCES}

Barber, M. \& Burston, J. (1955). Antibiotic resistant staphylococcal infection: A study of antibiotic sensitivity in relation to bacteriophage types. Lancet, ii, 578.

Barber, M. \& Whitehead, J. E. M. (1949). Bacteriophage types in penicillin resistant staphylococcal infections. Br. med. $J$. ii, 565 .

Barber, M. \& Wildy, P. (1958). A study of the antigenic specificity of staphylococcal coagulase in relation to bacteriophage group. J. gen. Microbiol. 18, 92.

Blair, J. E. \& CARR, M. (1960). The techniques and interpretation of phage typing of staphylococci. J. Lab. clin. Med. 55, 650.

Blair, J. E. \& Williams, R. E. O. (1961). Phage typing of staphylococci. Bull. Wld Hlth Org. 24, 2771.

Christensen, J. R. (1961). On the process of host-controlled modification of bacteriophage. Virology, 13, 40.

Cowan, S. T. (1939). Classification of staphylococci by slide agglutination. J. Path. Bact. 48, 169.

DELLA VIDA, B. L. (1957). Studi sulla tipizzazione batteriofagica de Micrococcus pyrogenes : Azione dei ceppi di propagazione. Giorn. Microbiol. 4, 138.

Hood, A. M. (1953). Phage typing of Staphylococcus aureus. J. Hyg., Camb. 51, 1.

Jones, D. J. \& KRUEger, A. P. (1951). A rapid slide plaque technique for bacteriophage assay. J. gen. Physiol. 34, 347.

Oeding, P. \& Williams, R. E. O (1958). The type classification Staphylococcus aureus: A comparison of phage-typing with serological typing. J. Hyg., Camb. 56, 445.

RALSTON, D. J. \& BAER, B. S. (1960). Improved method of phage assay by a plaque count method on microscope slides in trays. J. Bact. 79, 758.

Ralston, D. J. \& Baer, B. S. (1964a). Propagation of staphylococcal typing phages on a common host, Staphylococcus aureus $\mathrm{K} 1$, and host-controlled changes in their lytic range. J. gen. Microbiol. 36, 17.

Ralston, D. J. \& Baer, B. S. (1964b). Host-controlled changes of staphylococcal phage $3 \mathrm{C}$ affecting its broad group typing pattern. J.gen. Microbiol. 36, 25.

Ralston, D. J. \& Krueger, A. P. (1952). Phage multiplication on two hosts: Isolation and activity of variants of staphylococcal phage P1. Proc. Soc. exp. Biol., N.Y. 80, 217.

Ralston, D. J. \& KruEger, A. P. (1954). The isolation of a staphylococcal phage variant susceptible to an unusual host control. J. gen. Physiol. 37, 685.

Ralston, D. J., Baer, B. S., Lieberman, M. \& Krueger, A. P. (1961). Virolysin, a virusinduced lysin: Its appearance and function in phage-infected staphylococci. J. gen. Microbiol. 24, 313.

RIPPON, J. (1956). The classification of bacteriophages lysing staphylococci. J. Hyg., Camb. 54, 213.

Rountree, P. M. (1947). Staphylococcal bacteriophages. II. Bacteriophage adsorption by staphylococci. Austr. J. exp. Biol. Med. Sci. 25, 9.

Rountree, P. M. (1949a). The phenomenon of lysogenicity in staphylococci. J. gen. Microbiol. 3, 153.

Rountree, P. M. (1949b). The serological differentiation of staphylococcal bacteriophages. J. gen. Microbiol. 3, 164 .

Rountree, P. M. (1956). Variations in a related series of staphylococcal bacteriophages. J. gen. Microbiol. 15, 266. 
Wallmark, G. \& Finland, M. (1961). New phages active against staphylococci that are resistant to the conventional phage set. Proc. Soc. exp. Biol., N.Y. 106, 73.

Williams, R. E. O. \& RipPon, J. E. (1952). Bacteriophage typing of Staphylococcus aureus. J. Hyg., Camb. 50, 320.

Williams Smith, H. (1948a). Investigations of the typing of staphylococci by means of bacteriophage. I. The origin and nature of lysogenic strains. J. Hyg., Camb. 46, 74.

Williams Smith, H. (1948b). Investigations on the typing of staphylococci by means of bacteriophage. II. The significance of lysogenic strains in staphylococcal type designation. J. Hyg., Camb. 46, 82. 